Original Article

Artigo Original

Priscila Cruvinel Villa Sthella Zanchetta ${ }^{2}$

Keywords

Child Development

Auditory Perception

Otitis Media

Sensory Deprivation

Hearing Loss, Conductive

Descritores

Desenvolvimento Infantil

Percepção Auditiva

Otite Média

Privação Sensorial

Perda Auditiva Condutiva

Correspondence address:

Sthella Zanchetta

Departamento de Oftalmologia

Otorrinolaringologia e Cirurgia de Cabeça e Pescoço do Hospital das Clínicas da Faculdade de Medicina de Ribeirão Preto da Universidade de São Paulo Avenida Bandeirantes, $3.900,12^{\circ}$ andar, Monte Alegre, Ribeirão Preto (SP), Brasil, CEP: 14049-900.

E-mail: zanchetta@fmrp.usp.br

Received: 01/14/2014

\section{Auditory temporal abilities in children with history of recurrent otitis media in the first years of life and persistent in preschool and school ages}

\author{
Habilidades auditivas temporais em crianças com \\ histórico de otite média nos primeiros anos de vida \\ e persistente nas idades pré-escolar e escolar
}

\begin{abstract}
Purpose: To study the temporal auditory ordering and resolution abilities in children with and without a history of early OME and ROME, as well as to study the responses according to age. Methods: A total of 59 children were evaluated, and all of them presented pure tone thresholds within the normal range at the time of the conduction of the hearing tests. The children were divided into two groups according to the occurrence of episodes of recurrent otitis media. Then, each group was divided into two subgroups according to age: 7- and 8-year olds, and 9- and 10-year olds. All children were assessed with standard tests of temporal frequency (ordination) and gaps-in-noise (resolution). Results: For the temporal abilities studied, children with a history of otitis media presented significantly lower results compared to the control group. In the frequency pattern test, the correct answers increased with age in both groups. In the identification of silence intervals, the control group showed no change in threshold regarding to age, but this change was present in the group with a history of otitis media. Conclusion: Episodes of otitis media with effusion in the first year of life, recurrent and persistent in preschool and school ages, negatively influence the temporal ordering and resolution abilities.
\end{abstract}

\section{RESUMO}

Objetivo: Estudar as habilidades auditivas temporais de ordenação e resolução em crianças sem e com antecedentes de otite média com efusão precoce e recorrente, assim como estudar as repostas em função da idade. Métodos: Foram avaliadas 59 crianças, todas com limiares tonais dentro da normalidade no momento da realização dos testes auditivos. As crianças foram divididas em dois grupos, de acordo com a ocorrência ou não de episódios de otite média com efusão recorrente. Em um segundo momento, cada um dos grupos foi subdividido em dois subgrupos em função da idade: 7 e 8, e 9 e 10 anos. Todas as crianças foram avaliadas com os testes temporais de padrão de frequência (ordenação) e Gap-In-Noise (resolução). Resultados: As crianças com antecedentes de otite média apresentaram resultados inferiores, de forma significativa, quando comparados ao grupo controle, para as habilidades temporais estudadas. No teste de padrão de frequência, as respostas corretas aumentaram em função da idade nos dois grupos. No teste de identificação de intervalos de silêncio, não houve alteração no limiar em função da idade no grupo controle, mas houve para o grupo com antecedente de otite média. Conclusão: Episódios de otite média com efusão, ainda no primeiro ano de vida, recorrentes e persistentes em idade pré-escolar e escolar, influenciam negativamente as habilidades temporais de ordenação e resolução.

Study carried out at the Department of Ophthalmology, Otorhinolaryngology and Head and Neck Surgery, Faculdade de Medicina de Ribeirão Preto, Universidade de São Paulo - USP - Ribeirão Preto (SP), Brazil.

(1) Graduate Program, Department of Ophthalmology, Otorhinolaryngology and Head and Neck Surgery, Faculdade de Medicina de Ribeirão Preto, Universidade de São Paulo - USP - Ribeirão Preto (SP), Brazil.

(2) Department of Ophthalmology, Otorhinolaryngology and Head and Neck Surgery, Faculdade de Medicina de Ribeirão Preto, Universidade de São Paulo - USP - Ribeirão Preto (SP), Brazil.

Financial support: Fundação de Amparo à Pesquisa do Estado de São Paulo - FAPESP.

Conflict of interests: nothing to declare. 


\section{INTRODUCTION}

Otitis media is considered common in childhood, but children who present recurrent episodes require special attention. Studies tend to focus on the harmful effects of prolonged and chronic otitis media with effusion (OME) in aspects of general health, behavior, academic performance, language, and hearing ${ }^{(1-5)}$.

The effects of recurrent OME (ROME) on hearing acuity in the short and long terms are well documented ${ }^{(6,7)}$. However, results on the auditory central nervous system (ANCS), despite the vast amount of information available, are controversial ${ }^{(2,7-16)}$.

Studies focus on the premise of interdependence between episodes of OME and the change in tone thresholds, called fluctuating conductive hearing loss, because $80 \%$ children diagnosed with OME exhibit this kind of loss that acts as a sensory deprivation ${ }^{(8,15)}$. Another assumption concerns the critical period of maturation of the ANCS, because it is well documented that a greater likelihood of recurrence of OME is related to how early its first episode occurs, such as in the first years of life ${ }^{(17)}$. Special attention to periods referred as key on the maturation process of the ANCS is required, because experimental studies show structural and functional changes in synaptic relays that are important for sound processing, resulting from sensory deprivation due to middle ear disorders, such as in the cochlear nucleus, superior olive, and inferior colliculus $^{(13,18)}$. However, these studies show evidence of the ability of the ANCS to establish new neural networks after periods of deprivation.

The conflicting results on the effects of ROME on the ANCS can be observed and are well documented in studies $^{(3,10,15)}$, which raise different hypotheses for the diversity of results reported, such as the use of different methods, prospective versus retrospective, as well the manner of investigation of ROME episodes and questionnaires applied to parents versus monitoring of the middle ear function (tympanometry, otoscopy, pneumatic otoscopy, and presence of conductive hearing loss).

Two prospective cohort studies, however, periodically monitored the occurrence of OME in early years of life and, through this monitoring, authors drew different conclusions using the same test, the Masking Level Difference test ${ }^{(7,8)}$. In one of the studies, it was reported that only children identified with OME in their first years of life, in approximately $45 \%$ of the auditory monitoring visits, showed lower results $^{(8)}$. In another study, the lack of differences in hearing abilities was justified by the fact that perhaps the episodes of OME in this population were not chronic enough ${ }^{(7)}$.

Other aspects to be considered that may have caused the divergent results are the variety of tests used and auditory abilities evaluated, as well as the age at which children were evaluated. Speech recognition in monotonic, low redundancy condition is commonly used, and the speech-in-noise test is the most studied ${ }^{(7,11,12,14)}$. However, temporal processing is also often chosen, represented by resolution abilities ${ }^{(2,10,16)}$ as well as binaural interaction ${ }^{(7,8)}$. Regarding age, there is a difficulty in interpreting the results of behavioral tests of auditory processing in children younger than 7 , due of the aspect of the maturation phase of the ANCS and the demand for resources needed for the children to perform the tests ${ }^{(19)}$. One has to consider that many studies selected the age range between 5 and 6 years for the investigation of auditory abilities $^{(2,8,10,12)}$.

Considering the data presented above, this study aimed to assess the temporal auditory ordering and resolution abilities in children with and without a history of early OME and ROME, as well as to study the responses according to age.

\section{METHODS}

This study was conducted after approval of the research ethics committee of Hospital das Clínicas, Faculdade de Medicina de Ribeirão Preto, Universidade de São Paulo (USP) (HCRP protocol no. 13144/2009). All guardians were asked to authorize their children's participation and, in case of a positive reply, were asked to read and sign the free and informed consent form.

The sample comprised 59 children aged between 7 and 10 years, divided into two groups according to the occurrence of middle ear disorder episodes in early years of life.

The study group (SG) comprised 29 children, 18 males and 11 females, coming from two otolaryngology outpatient clinics from the public health system, who were active, that is, still had appointments during the period of this research. This group was divided in two: SG1, with 18 children aged between 7 and 8 years, and SG2, with 11 children aged between 9 and 10 years. The criteria for inclusion in these groups were the following: having the occurrence of the first episode of otitis, in the first year of life, documented in medical records, as well as at least four other episodes over a period of 12 months, under the age of three. The exclusion criteria were the following: malformations of the head and neck, presence of genetic and/or neurological syndromes, gestational age below 37 weeks, birth weight below 2,500 g, hospitalizations requiring respiratory support, history of neurological medical consultation, diagnosis of obstructive sleep apnea, virusseropositive for acquired immune deficiency syndrome, results of the audiological evaluation of air conduction thresholds (ACT) greater than $15 \mathrm{dBNA}$ at frequencies from 0.25 to $8 \mathrm{kHz}$, and the presence of air-bone gap greater than $10 \mathrm{~dB}$ at frequencies from 0.5 to $4 \mathrm{kHz}$.

The control group (CG) comprised 30 children, 15 males and 15 females. It was also divided in two subgroups: CG1, with 19 children aged between 7 and 8 years, and CG2, with 11 children aged between 9 and 10 years. Inclusion criteria for this group were being enrolled in a public school and no history of hearing loss of any nature. The exclusion criteria were established and checked on the day after the hearing evaluation, namely: hearing loss of any nature; identification of signs suggesting malformation of the head and neck, such as auricular appendages; air conduction thresholds (ACT) 
greater than $15 \mathrm{dBNA}$ at frequencies from 0.25 to $8 \mathrm{kHz}$; and the presence of air-bone gap greater than $10 \mathrm{~dB}$ at frequencies from 0.5 to $4 \mathrm{kHz}$, as well as alterations in the tympanometric curve and/or absence of acoustic reflex in at least one frequency between $0.5,1$, and $2 \mathrm{kHz}$, in any form, ipsilateral or contralateral.

Auditory sensitivity was assessed in all children through ATT and speech reception threshold. The whole CG and the SG with integrity of the tympanic membrane were measured for acoustic impedance and acoustic reflex. Due to some children of SG still showing the ventilation tube due to middle ear surgery, investigation of bone conduction threshold (BCT) was adopted, at frequencies from 0.5 to $4 \mathrm{kHz}$, in all 59 children, regardless of ACT. The presence of a difference of up to $10 \mathrm{~dB}$ between the ACT and BCT, at the same frequency, with ACT of up to 15 dBNA, was interpreted as normal acuity for its frequency and lack of secretion in the middle ear.

The acoustic immittance was measured using Madsen OTOflex 100 equipment by GN Otometrics with a probe tone of $226 \mathrm{~Hz}$, in all children with middle ear integrity. Compliance results between 0.2 and $1.7 \mathrm{~mL}$ and peak pressure between +50 and -100 daPa were adopted as normal values.

For the evaluation of the temporal ordering ability, the frequency pattern test $(\mathrm{FPT})^{(20)}$ was used, administered monotonically, $50 \mathrm{dBSL}$ above the overall average frequencies of $0.5,1$, and $2 \mathrm{kHz}$. The test consists of sequences, each including three tones, two of which are always the same, and one is different, alternating its position in each sequence. The tone of $1.430 \mathrm{~Hz}$ is called a high-pitched or "thin" tone, and the tone of $880 \mathrm{~Hz}$, a low-pitched or "thick" tone. Thus, sequences can be formed as follows: $1.430 \mathrm{~Hz}$ (thin) $-1.430 \mathrm{~Hz}$ (thin) $-880 \mathrm{~Hz}$ (thick); or $1.430 \mathrm{~Hz}$ (thin) $880 \mathrm{~Hz}$ (thick) $-1.430 \mathrm{~Hz}$ (thin); or even $880 \mathrm{~Hz}$ (thick) $1.430 \mathrm{~Hz}$ (thin) $-880 \mathrm{~Hz}$ (thick); and so forth. Children aged between 7 and 8 years and 11 months performed version one, called the child version. From children aged 9 on, version two was used. In version one, the duration of each stimulus is $500 \mathrm{~ms}$, with $300-\mathrm{ms}$ intervals between two stimuli and between the 10-s sequences. In version two, these parameters are $200 \mathrm{~ms}, 150 \mathrm{~ms}$, and $7 \mathrm{~s}$.

The FPT was applied in three steps. Step one was called discrimination, where 20 sequences were presented, each with 2 stimuli, being 10 sequences in each ear, and the child was asked to respond, after each sequence, if they were same or different. In step two, called nonverbal response, 60 sequences were presented, each with 3 stimuli, 30 for each ear. At that moment, the child was encouraged to imitate the model heard regarding tone frequency, according to the evaluator's model. In step three, called naming, again, 60 sequences were presented, composed of 3 stimuli, 30 to each ear. However, at that time, the names "thin" for the $1.430-\mathrm{Hz}$ stimuli and "thick" for the $880-\mathrm{Hz}$ stimuli were presented to the child. The FPT was performed in the following order: discrimination stage for right and left ears, nonverbal response stage for right and left ears, and naming stage for right and left ears. Only children with a success rate of $80 \%$ or higher in the discrimination stage went through the following stages.

To evaluate the ability of temporal resolution, the gapsin-noise (GIN) test ${ }^{(21)}$, consisting in the identification of silence gaps in noise, was used, applied monaurally, $50 \mathrm{dBSL}$ of the tritonal average of frequencies $0.5,1$, and $2 \mathrm{kHz}$. The test consists of the presentation of 6-s-long white noise tracks. In each track, a silence interval, called the gap, may or may not be present. When present, these gaps can occur once, twice, or thrice, and may have a duration of 2, 3, 4, 5, $6,8,10,12,15$, and $20 \mathrm{~ms}$. The interval between the stimulus tracks (noise) is $5 \mathrm{~s}$, and the test has four tracks, with the number of white noise tracks in each varying between 29 and 36. But in all of them, the number of intervals that occur is the same. Only two tracks were applied, one to each ear. Before the test, a practice track was performed with 10 stimuli, and at that stage, the child was instructed to perform the test as many times as were necessary for the understanding of the task. This test studied the gap threshold of each ear, determined by the shortest time interval in which the child identified four of the six events.

\section{Study design}

The study aimed to verify the hypothesis of the existence of differences in the results of temporal tests between the two test groups, as well as intragroup, due to age. On this basis, the results of temporal tests were termed as dependent variables for the study; other results such as age, gender, and tonal thresholds were considered as independent variables.

In the initial analysis, the sample results showed no normal distribution. Thus, the description of all results included the median values, using the interquartile measures for statistical analysis. The Wilcoxon test was conducted in the intragroup study, and the Mann-Whitney test for analysis between groups. The study of the distribution of age groups in the sample was performed through Dunn's test. The Fisher's exact test was used for the distribution of genders. The level of significance was $0.05(5 \%)$. When the result was significant, it was noted with an asterisk (*).

\section{RESULTS}

The constitution of each group regarding age was analyzed between the SG and the CG, considering the overall sample and subgroups (Table 1).

When considering the age of the children who made up the SG and the CG, regardless of the subdivisions, no difference was observed between them. The central, mean, and median measures are similar, as well as the minimum and maximum ages. In the study between the groups, considering the same age range among them, there was no difference, that is, SG1 compared to CG1, aged 7 and 8 years, and SG2 compared to CG2, aged 9 and 10 years.

The composition of the groups regarding gender was analyzed within groups, that is, between different ages in each group and between groups of the same age. In any 
Table 1. Descriptive and comparative analysis of age in the groups and subgroups

\begin{tabular}{|c|c|c|c|c|c|}
\hline Groups and Subgroups & $\mathrm{n}$ & Mean (SD) & Median & Min-Max & $95 \% \mathrm{Cl}$ \\
\hline \multicolumn{6}{|l|}{$S^{*}$} \\
\hline Total & 29 & $8.4(1.2)$ & 8.11 & $7.0-10.9$ & $7.966-9.905$ \\
\hline SG1: 7 and 8 years & 18 & $7.59(0.5)$ & 7.4 & $7.0-8.7$ & $7.334-7.846$ \\
\hline SG2: 9 and 10 years & 11 & $7.8(0.5)$ & 7.8 & $7.0-8.9$ & $7.535-8.108$ \\
\hline \multicolumn{6}{|l|}{$\mathrm{CG}^{*}$} \\
\hline Total & 30 & $8.5(1.0)$ & 8.4 & $7.0-10.9$ & $8.100-8.909$ \\
\hline CG1: 7 and 8 years & 19 & $9.8(0.6)$ & 9.7 & $9.0-10.9$ & $9.380-10.256$ \\
\hline CG2: 9 and 10 years & 11 & $9.0(0.5)$ & 9.6 & $9.0-10.7$ & $9.289-10.078$ \\
\hline
\end{tabular}

*Dunn's test $-\mathrm{p}$-value $=0.36$

Caption: SD = standard deviation; Min-Max = minimum and maximum; $95 \% \mathrm{Cl}=$ confidence interval of $95 \%$

of the analyses, there was a predominance of one gender in the population, because the results showed no difference (Fisher's exact test - SG1 x SG2: p=1.0, 95\% CI $0.6128-2.008$; CG1 x CG2: $\mathrm{p}=0.64,95 \%$ CI $0.6431-1.920$; SG1 x CG1: $\mathrm{p}=0.74,95 \%$ CI $0.6009-2.386 ;$ SG2 x CG2: $\mathrm{p}=1.0,95 \%$ CI $0.5166-2.788$

\section{Auditory sensitivity}

Because some children in the SG still presented the vent pipe due to otologic surgery for OME, thus impeding tympanometry, the comparison between the ACT and BCT became necessary in all children, to investigate and show that they had the same middle ear condition, lack of secretion. Initially, the ACT and BCT were analyzed and compared in the two groups, because the tone thresholds are not influenced by the participants' age in the groups studied. In SG, no differences between the right and left ears were observed at frequencies $0.25-8 \mathrm{kHz}(0.25 \mathrm{kHz}$, $\mathrm{p}=0.40 ; 0.5 \mathrm{kHz}, \mathrm{p}=0.48 ; 1 \mathrm{kHz}, \mathrm{p}=0.101 ; 2 \mathrm{kHz} \mathrm{p}=0.15$; $3 \mathrm{kHz}, \mathrm{p}=0.627 ; 4 \mathrm{kHz}, \mathrm{p}=0.694 ; 6 \mathrm{kHz}, \mathrm{p}=0.642$; and $8 \mathrm{kHz}$, $\mathrm{p}=0.587)$. In $\mathrm{CG}$, no differences were observed between the ears' ACT $(0.25 \mathrm{kHz}, \mathrm{p}=0.11 ; 0.5 \mathrm{kHz}, \mathrm{p}=0.329 ; 1 \mathrm{kHz}$, $\mathrm{p}=0.827 ; 2 \mathrm{kHz}, \mathrm{p}=0.07 ; 3 \mathrm{kHz}, \mathrm{p}=0.518 ; 4 \mathrm{kHz}, \mathrm{p}=0.08$; $6 \mathrm{kHz}, \mathrm{p}=1.00$; and $8 \mathrm{kHz}, \mathrm{p}=0.657$ ).

The same study was performed with the BCT, and no difference in this measure was observed between the ears in both groups ( $\mathrm{SG}: 0.5 \mathrm{kHz}, \mathrm{p}=0.43 ; 1 \mathrm{kHz}, \mathrm{p}=1.00 ; 2 \mathrm{kHz}$, $\mathrm{p}=0.317 ; 3 \mathrm{kHz}, \mathrm{p}=0.140$; and $4 \mathrm{kHz}, \mathrm{p}=0.19$; $\mathrm{CG}: 0.5 \mathrm{kHz}$, $\mathrm{p}=0.207 ; 1 \mathrm{kHz}, \mathrm{p}=0.63 ; 2 \mathrm{kHz}, \mathrm{p}=0.15 ; 3 \mathrm{kHz}, \mathrm{p}=0.16$, and $4 \mathrm{kHz}, \mathrm{p}=0.524$ ). These results enabled the addition of both ears, right and left, when comparing the thresholds related to groups, doubling the number of the sample. The SG, with 29 subjects, now contained 58 ears, and the CG had 30 subjects and 60 ears.

The comparative study of the ACT and BCT between the $\mathrm{SG}$ and $\mathrm{CG}$ can be visualized in Figure 1. No differences in the ACT were observed between the SG and the CG in any of the investigated frequencies (Figure $1 \mathrm{~A}, \mathrm{p}>0.05$ ). The minimum value was $-5 \mathrm{dBNA}$, and the maximum was $15 \mathrm{dBNA}$ $(0.25 \mathrm{kHz}, \mathrm{p}=0.98 ; 0.5 \mathrm{kHz}, \mathrm{p}=0.39 ; 1 \mathrm{kHz}, \mathrm{p}=0.290 ; 2 \mathrm{kHz}$, $\mathrm{p}=0.402 ; 3 \mathrm{kHz}, \mathrm{p}=0.836 ; 4 \mathrm{kHz}, \mathrm{p}=0.279 ; 6 \mathrm{kHz}, \mathrm{p}=0.577$; and $8 \mathrm{kHz}, \mathrm{p}=0.553)$. No differences were observed in the
BCT between the two groups as well (Figure 1B, p $>0.05$ ). The minimum value was $-5 \mathrm{dBNA}$ and maximum was 10 dBNA (SG: $0.5 \mathrm{kHz}, \mathrm{p}=0.59 ; 1 \mathrm{kHz}, \mathrm{p}=0.738 ; 2 \mathrm{kHz}$, $\mathrm{p}=0.978 ; 3 \mathrm{kHz}, \mathrm{p}=0.523$; and $4 \mathrm{kHz}, \mathrm{p}=0.19$ ).

\section{Results of temporal tests between groups}

As a result of the reduction in the sample number due to the subdivision in groups depending on the age, a study was initially conducted to determine the viability of adding

(A) Air Conduction Threshold

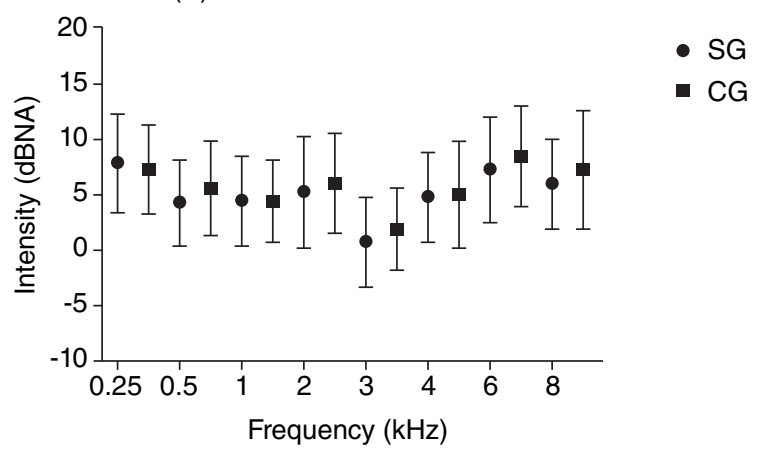

(B) Bone Conduction Threshold

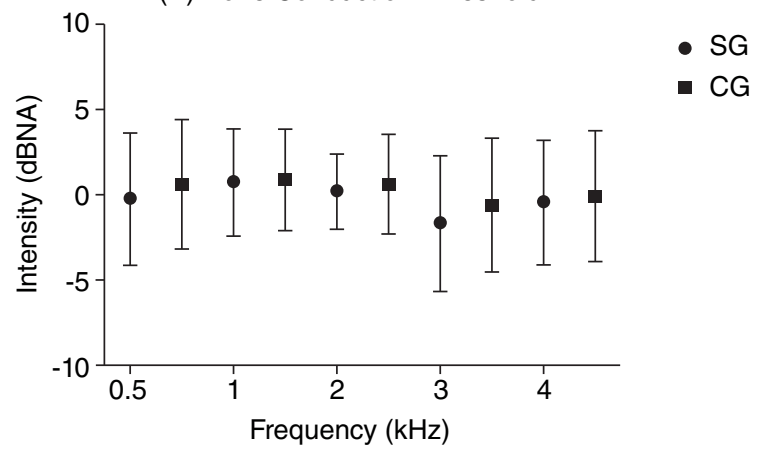

Caption: SG: study group; CG: control group

Figure 1. Representative graph of the tonal thresholds in the study group and the control group, with median and interquartile values 
both ears for the analysis. Thus, in each subgroup, the results of each test were studied for both the right and left ears (Figure 2). In the FPT, nonverbal response and naming, and the GIN test, in all age groups and in all subgroups, showed no difference between ears ( $p>0.05$ ), allowing thus the doubling of the sample by adding both ears. The SG1 (ages 7 and 8 years), with 18 subjects, is now composed of 36 ears; the SG2 (ages 9 and 10 years), with 11 subjects, went on to have 22 ears; the GC1 (ages 7 and 8 years), with 19 subjects, now consisted of 38 ears; and finally, the GC2 (ages 9 and 10 years), with 11 subjects, went on to have 22 ears.

The next step was to verify the performance between groups considering the same age group (subgroups) for each of the tests. Descriptive analysis of each test and of all subgroups is shown in Table 2.

In the FPT, considering the nonverbal response, the SG had a lower percentage of correct answers when compared with the CG for both the age range (7-8 years and 9-10 years). The same result was observed for the stage of naming the characteristic of the frequency. The number of correct responses was significantly lower in the SG when compared with the GC in the same age group.
For the GIN test, in ages 7-8 years, although both the mean and the median of the thresholds of the SG and CG were close, analysis, through the values of quartiles, suggests that they are significantly different (Table 2), with higher values in the SG compared to the CG. The same consideration about the similarity of the core measures and the use of interquartile measures should be taken when comparing the values of the threshold for GIN in ages 9 and 10 years (Table 2). Although the SG has the same mean and median values of the CG, $5 \mathrm{~ms}$, the $\mathrm{SG}$ showed values up to $10 \mathrm{~ms}$, which were higher than those in the CG, whose maximum value was $6 \mathrm{~ms}$.

\section{Results of intragroup temporal tests, according to age}

For this analysis, the same procedures as in the previous analysis were kept, that is, the addition of the right and left ears (Table 3).

For the FPT, in the nonverbal response stage, the two groups showed significant differences between ages, with responses at the age of 7 and 8 years lower than those in the 9 and 10 years age range. In the same temporal test,

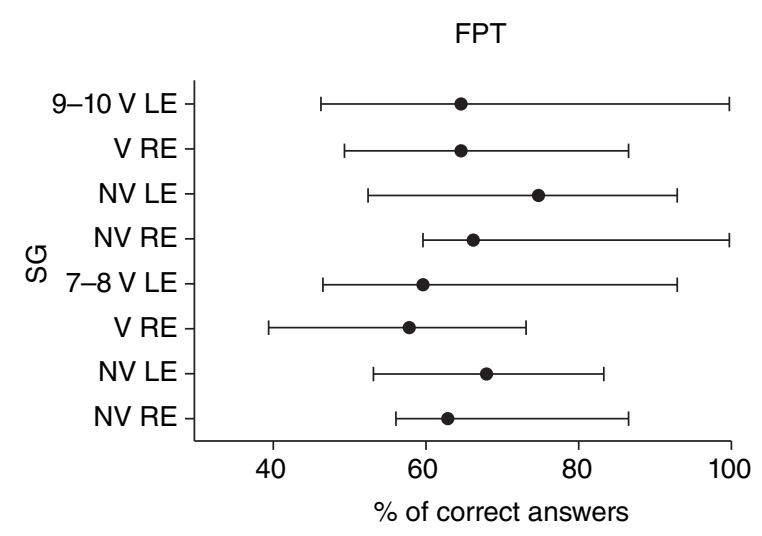

GN

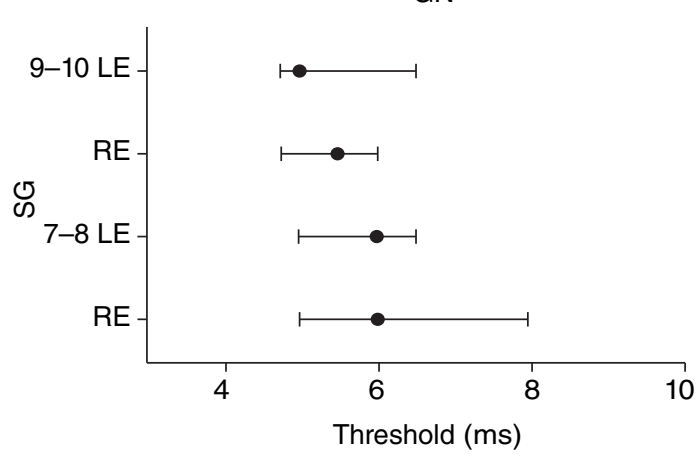

FPT

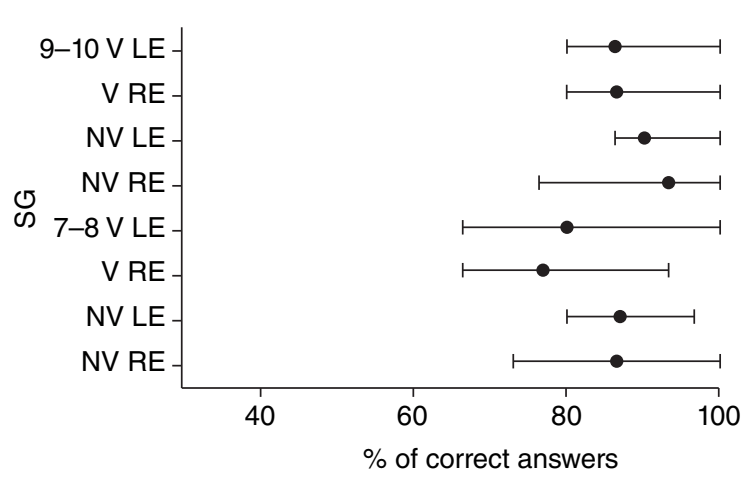

GN

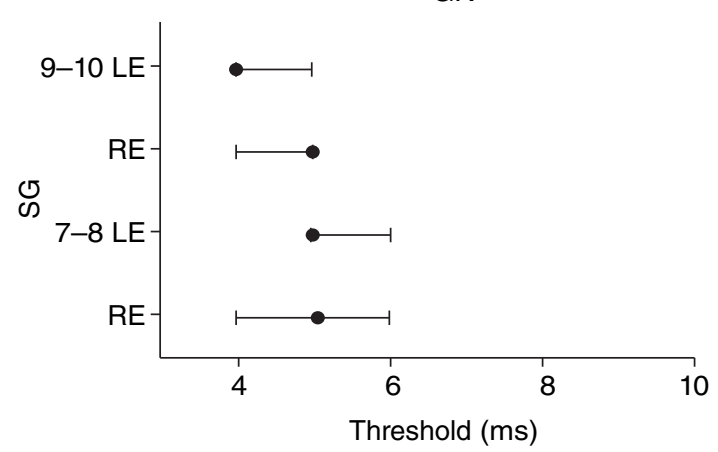

\footnotetext{
Caption: FPT = frequency pattern test; GIN = gaps-in-noise; $m s$ = milliseconds; RE = right ear; LE = left ear; SG = study group; CG = control group; NV = nonverbal; $\mathrm{V}=$ verbal; $9-10$ = age group of 9 and 10 years; $7-8=$ age group of 7 and 8 years; Wilcoxon's test = FPT; NV (7-8 years) = CG - RE x LE, $p=0.43, S G-R E x$ LE, $\mathrm{p}=0.07$; FPT, NV (9 and 10 years) = CG - RE x LE, $p=0.09$, SG - RE x LE, p=0.12; FPT, V (7-8 years) = CG - RE x LE, p=0.59, SG - LE x RE, p=0.41; FPT, V (9

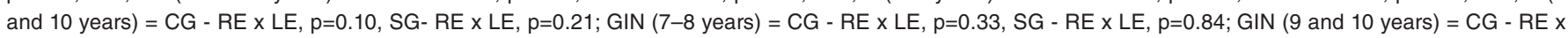
LE, $p=034$, SG - RE $x$ LE, $p=0.15$
}

Figure 2. Graph of the results of temporal tests, by ear, by subgroups, with median and interquartile values 
Table 2. Descriptive analysis of the results of temporal tests by subgroup

\begin{tabular}{|c|c|c|c|c|}
\hline \multirow{2}{*}{ Group } & \multirow{2}{*}{$\begin{array}{c}\text { Age } \\
\text { (years) }\end{array}$} & \multicolumn{2}{|c|}{ FPT } & \multirow{2}{*}{$\frac{\text { GIN }}{\text { Threshold (ms) }}$} \\
\hline & & Nonverbal & Naming & \\
\hline SG1 & $7-8$ & & & \\
\hline Mean (SD) & & $66.8(8.7)$ & $58.4(10.8)$ & $6.2(1.7)$ \\
\hline Median & & 66.6 & 58.3 & 6.0 \\
\hline Min-Max & & 53.3-86.6 & $40.0-73.3$ & $4-12$ \\
\hline SG2 & $9-10$ & & & \\
\hline Mean (SD) & & $75.4(13.0)$ & $68.6(14.7)$ & $5.6(1.7)$ \\
\hline Median & & 71.6 & 64.9 & 5.0 \\
\hline Min-Max & & $50.0-100.0$ & $50-93.3$ & $4-10$ \\
\hline CG1 & $7-8$ & & & \\
\hline Mean (SD) & & $87.2(5.9)$ & $79.3(7.4)$ & $5.2(0.7)$ \\
\hline Median & & 86.6 & 80.0 & 5.0 \\
\hline Min-Max & & $73.3-100.0$ & $66.6-100.0$ & $4.0-6.0$ \\
\hline CG2 & $9-10$ & & & \\
\hline Mean (SD) & & 92.5 (5.3) & $88.3(5.8)$ & $4.5(0.5)$ \\
\hline Median & & 93.3 & 86.6 & 5.0 \\
\hline Min-Max & & $76.6-100.0$ & $80.0-100.0$ & $4.0-6.0$ \\
\hline
\end{tabular}

${ }^{*}$ Significant results according to statistics

Caption: FPT = frequency pattern test; GIN = gaps-in-noise; $\mathrm{ms}$ = milliseconds; $\mathrm{SG}=$ study group; $\mathrm{CG}$ = control group; $\mathrm{SD}$ = standard deviation; MinMax: minimum and maximum. Result of the Mann-Whitney test: age group of 7-8 years (SG1 $\mathrm{x}$ CG1); FPT, nonverbal $=p=0.001^{*} ; \mathrm{FPT}$, verbal: $\mathrm{p}=0.02^{*} ; \mathrm{GIN}, \mathrm{p}=0.02^{*}$; age group of $9-10$ years (SG2 x CG2); FTP, nonverbal: $p=0.02^{*}$; FPT, verbal: $p=0.01^{*}$; $\mathrm{GIN}, p=0.02^{*}$

Table 3. Intragroup comparative analysis according to age

\begin{tabular}{lccc}
\hline Groups & Test & Age group & p-value \\
\hline SG & FPT, nonverbal & $7-8 \times 9-10$ & $0.02^{*}$ \\
SG & FPT, naming & $7-8 \times 9-10$ & $0.03^{*}$ \\
SG & GIN & $7-8 \times 9-10$ & $0.001^{*}$ \\
CG & FTP, nonverbal & $7-8 \times 9-10$ & $0.04^{*}$ \\
CG & FTP, naming & $7-8 \times 9-10$ & $0.002^{*}$ \\
CG & GIN & $7-8 \times 9-10$ & 0.09 \\
\hline
\end{tabular}

${ }^{*} \mathrm{p} \leq 0.05$

Caption: FPT = frequency pattern test; GIN = gaps-in-noise; $\mathrm{SG}$ = study group; $C G=$ control group

in the naming stage, significantly lower responses were also observed between ages in both groups.

In the GIN test, different results were observed for the SG and CG. The threshold for GIN was lower with increasing age in the SG, $6 \mathrm{~ms}$ for ages 7 and 8 years and $5 \mathrm{~ms}$ for ages 9 and 10 years, but in the CG, it has remained the same: $5 \mathrm{~ms}$.

\section{DISCUSSION}

The need for measurement and comparison between the $\mathrm{ACT}$ and BCT can be justified by the history of OME, considering that some children of the SG still did not have the indication for tympanometry. The research of the BCT and the exclusion of children with air-bone differences greater than $10 \mathrm{~dB}$ in the same frequency seemed the best method of investigating the absence of secretion in the middle ear, because the ACT presenting values within the normal range do not exclude this condition ${ }^{(22)}$. The results of this part of the study allowed us to affirm that evaluations of temporal auditory skills were conducted in the two groups under the same condition of sensitivity and without the presence of OME, which is an important factor, as its presence causes delay in the propagation of sound waves, mainly between 1 and $6 \mathrm{kHz}^{(23)}$. Thus, the differences between groups in temporal auditory skill tests may not be related to this key factor.

Temporal tests are suggested to compose the evaluation of the auditory processing ${ }^{(19)}$. The basis for this suggestion is its relation with the perception of aspects of speech ${ }^{(24)}$, such as prosody and suprasegmental features.

The comparative study between the two ears in each group, in the two tests (FPT and GIN), showed no difference between them, which reflects the absence of the effect of the ear on these two skills, a result that was already documented by other studies ${ }^{(25-29)}$.

The FPT is a test of temporal ordering of frequency patterns, a skill that is performed on cortical level by the two brain hemispheres, with the participation of the corpus callosum for the transfer between hemispheres, for the task of imitation and naming to be performed ${ }^{(24)}$. Children of the SG showed inferior results compared to those of the CG in the two tasks. The FPT, with the naming task was also used in another study on the effects of ROME about hearing, where children were assessed at ages $8-10$ years $^{(16)}$. The authors reported that, when comparing the scores of correct answers between groups, those with a history of otitis did not differ from the CG. However, when considering the test result as a categorical variable, normal or altered, there was a difference between them ${ }^{(16)}$.

It is important to highlight some issues to allow understanding of the lack of agreement of the results for the comparative analysis between the absolute scores of the FPT between this study and the work cited ${ }^{(16)}$. Initially, it can be noted that this test has great variability of results in the population aged under 11 years, thus limiting its clinical use in younger children ${ }^{(25,26)}$. The other issue is focused on the use of different versions of FPT that were used, and the version used in this study in the duration of the stimuli and interstimulus interval, among other characteristics, which are higher than in the study cited ${ }^{(16)}$. In the execution of this study, it is noteworthy that only children who showed the ability to discriminate between the two frequencies that make up the test performed it. Thus, it was ensured that any difficulties in carrying out the stages referred to the ordering ability, and not to the discrimination ability.

The version of the FPT used here was used in another study ${ }^{(26)}$ in children aged 7 and over and with no specific development complaints. In the nonverbal response stage, the cited work described a similar percentage of correct answers to the CG presented here and higher to those of the SG, in both age groups. However, for the ages of 9 and 10 years, the results are inconsistent, as the percentage of correct answers in the CG is superior to that of those for the same age. 
As for performance according to age, the results showed higher scores on the temporal ordering for frequency standards for the two types of responses, nonverbal and naming for both the SG and the CG. The best performance arising from increasing age is documented by other studies ${ }^{(24,25)}$, regardless of authorship of the FPT, and is attributed to the maturation process of neural components that constitute the auditory pathways ${ }^{(30)}$. This result is particularly important to the SG, because although the condition of ROME interferes with the performance of the ability, compared with children of the same age, children remain in the route of the maturation process. That is, this can be interpreted as delay the development of the ability ${ }^{(30,31)}$.

The ability of temporal resolution or discrimination refers to the shortest time in which one can identify the existence of two signals, and is also called temporal auditory acuity, or minimum integration time ${ }^{(24)}$. Among the possible tests to assess this ability, the GIN evaluates the shortest silence interval in the noise, and has its findings documented in the pediatric population ${ }^{(27-29)}$.

There was a similarity of the central measure of the threshold in GIN between the CG with those documented for the Brazilian population ${ }^{(16,28,29)}$, but this similarity is also true for the SG, although, in the analysis between groups, the SG showed higher values than the CG. It is noteworthy that this difference was due to the SG including some members with the lowest thresholds, discrepantly, $12 \mathrm{~ms}$ for ages 7 and 8 years, and $10 \mathrm{~ms}$ for ages 9 and 10 years, whereas in the CG, the maximum threshold was $6 \mathrm{~ms}$, as documented in regulation studies for the test.

The temporal resolution ability was evaluated in other studies in children with a history of $\mathrm{OME}^{(2,10,16)}$. The GIN test was also used in one of them ${ }^{(16)}$, and the results agree with those presented here, showing that children with a history of ROME have higher thresholds, compared to children of the same age without this condition. In two other studies with different procedures for assessing the temporal resolution, the authors found no differences between the SG and the $\mathrm{CG}^{(2,10)}$.

The first study evaluated the temporal resolution ability in children with and without a history of otitis media ${ }^{(2)}$. Children aged 5 years were recruited from the proof of episodes of otitis through hospital records, considered positive with the occurrence of seven episodes in the first 3 years of life. The authors also found no differences in the temporal resolution test between children with and without episodes of OME.

In the second study ${ }^{(10)}$, the authors used two different temporal resolution tests, one of which included the task of identifying a pure tone with a duration of $200 \mathrm{~ms}$ in the presence of noise, whereas the other included the task of detecting a brief pure tone of $20 \mathrm{~ms}$, presented in different positions (in time) in relation to the noise bandwidth. Children under 5 years showed no different results on the basis of ROME occurrence, but, on the other hand, children aged 8 years showed a difference. However, it was attributed to the presence of a bias, the form of recruitment of 8-yearold children. According to them, because OME is a typical disease of early life and asymptomatic, children, who were having medical consultations at the age of 8 years, could present this condition due to comorbidities, such as inattentiveness, delayed language acquisition, and/or behavioral disorder, which could worsen the condition of OME and/or interfere with the auditory ability under study. To elucidate this hypothesis, the same authors conducted a second study with children of the same age as before, but who had their middle ear condition monitored early in life. However, this time, authors found no differences in outcomes between episodes of ROME and the performance in the temporal resolution test.

Some hypotheses can be raised for the results presented in this study not being corroborated. Initially, the issue raised related to the children recruitment bias placed by the authors of the second study ${ }^{(10)}$, and we believe that this issue cannot be used to explain the findings in this study, as children who composed the SG had their first OME episode in their first year of life and remained in the doctor's office because of its recurrence, therefore are not new cases. Thus, it is possible to say that children studied here, due to this characteristic, can be considered as chronic cases of recurrence of the disease, which can illustrate its severity, which justifies the results showed here not presenting any relation to these two studies ${ }^{(2,10)}$.

Another hypothesis is related to whether the episodes of OME in these two studies, during the first years of life, were chronic enough. This argument was used to justify a study that also found no difference in the results of the binaural interaction test in children aged 6 years, who had the middle ear function monitored during the first years of $\operatorname{life}^{(7)}$.

The third hypothesis is also related to the recurrence of episodes of OME, because a connection was established between the worst performance in the speech-in-noise test and the magnitude of fluctuating conductive hearing loss due to disease in the first years of life, and not the number of episodes of the disorder ${ }^{(14,15)}$. In this study, it was not possible to obtain back data on auditory acuity.

The results of SG relative to lower performance in temporal tests shown here are supported by electrophysiological studies of the auditory pathway, both in early ${ }^{(7)}$ and in late potentials ${ }^{(13)}$. The delay of absolute latency of wave $\mathrm{V}$, as well as greater I-V interpeak value in the brainstem auditory evoked potential at the age of 8 was positively associated with a higher frequency of OME episodes in the first years of life $^{(7)}$. The prolongation of I-V and I-III interpeak latencies were also related to ROME in early life in children aged 3, but not those aged 4 and 5 years ${ }^{(13)}$. In fact, the changes found in the brainstem auditory evoked potential may be justified, as experimental studies identified structural changes in the cochlear nuclei, medial olivary complex, and inferior colliculus, that is, from the low trunk to the high trunk ${ }^{(18)}$. These neural structures are responsible, respectively, for waves III and for the IV-V complex ${ }^{(32)}$. 
Regarding late potentials, a lower magnitude of amplitude was observed in the $\mathrm{P} 1, \mathrm{~N} 1, \mathrm{P} 2$, and $\mathrm{N} 2$ registers in a group with ROME at 3 years of age, but not at 4 and 5 years $^{(13)}$. However, the results of the latency of P1 and N1 registers did not differentiate the groups with and without ROME at 2 years of age ${ }^{(33)}$.

Another late potential study in children with a history of ROME is the Mismatch Negativity, whose results showed no variations of registers in the CG; for example, against the deviant stimulus of frequency, the group with a history of ROME showed greater lateralization of registers in the left hemisphere, with greater amplitude, whereas the CG presented lateralization on the right hemisphere ${ }^{(33)}$. The authors name this response atypical pre-attentive auditory discrimination and hypothesized its occurrence as a cortical compensation to the input signal degraded by otitis. In any case, it is important to note that changes in the late auditory evoked potential suggest the involvement of cortical structures $^{(30)}$, in the same way as the behavioral tests that assess temporal processing ${ }^{(16,24)}$.

Regarding the absence of corroboration of these electrophysiological results in the population with $\operatorname{ROME}^{(13,33)}$, it is prudent to primarily consider the differences in the acoustic characteristics of the stimuli (speech versus specific frequency) and analysis parameters (amplitude versus latency). Another important consideration is the age at which children were assessed (2, 3, 4, and 5 years). Neuroplasticity is a biological response, and there are several factors that contribute to its occurrence, including age and the etiology of the disorder that affected the central nervous system. Thus, it is assumed that children with ROME have neural resources for new connections for processing the auditory information ${ }^{(33)}$ and present unique opportunities for the auditory functional recovery, as this condition occurs most frequently in the first years of life and decreases with increasing age ${ }^{(1)}$, which is an important factor, because the maturation of ACNS extends up to the age of 12 to 14 years $^{(30)}$.

Results showing that children in the SG improved their test scores as a function of increasing age may be related to a delay in the development of abilities that constitute the auditory temporal processing ${ }^{(30,31)}$. Still, these results may help clinicians involved in the management of this population in the decision-making process for referral to assessment of auditory processing and, in turn, the sooner they do it, the better the utilization of the neuroplasticity process of the ANCS they provide ${ }^{(7)}$.

\section{CONCLUSION}

Children with OME in the first years of life, recurrent in pre-school and school ages, presented a lower performance for temporal ordering and resolution auditory abilities when compared to children matched according to gender and age, but with no history of the same disease. In this condition, children with ROME showed improved performance of the two abilities, depending on the age group.
*PCV was responsible for the collection and tabulation of data, initiated the results analysis, and drafting of the manuscript; SZ was responsible for the study project and design, data analysis, and drafting of the manuscript.

\section{REFERENCES}

1. Paradise JL, Dollaghan CA, Campbell TF, Feldman HM, Bernard BS, Colborn DK, et al. Language, speech sound production, and cognition in three-year-old children in relation to otitis media in their first three years of life. Pediatrics. 2000;105(5):1119-30.

2. Nittrouer S, Bruton LT. The role of early language experience in the development of speech perception and phonological processing abilities: evidence from 5-year-olds with histories of otitis media with effusion and low socioeconomic status. J Commun Disord. 2005;38(1):29-63.

3. Zumach A, Chenault MN, Anteunis LJ, Gerrits E. Speech perception after early-life otitis media with fluctuating hearing loss. Audiol Neurootol. 2011;16(5):304-14.

4. Williams CJ, Jacobs AM. The impact of otitis media on cognitive and educational outcomes. Med J Aust. 2009;191:S69-S72.

5. Rosenfeld RM, Schwartz SR, Pynnonen MA, Tunkel DE, Hussey HM, Fichera JS, et al. Clinical practice guideline: tympanostomy tubes in children. Otolaryngol Head Neck Surg. 2013;149(1):S1-S35.

6. Gravel JS, Wallace IF. Effects of otitis media with effusion on hearing in the first 3 years of life. J Speech Lang Hear Res. 2000;43(3):631-44.

7. Gravel JS, Roberts JE, Roush J, Grose J, Besing J, Burchinal M, et al. Early otitis media with effusion, hearing loss, and auditory processes at school age. Ear Hear. 2006;27(4):353-68.

8. Hogan SC, Moore DR. Impaired binaural hearing in children produced by a threshold level of middle ear disease. J Assoc Res Otolaryngol. 2003;4(2):123-9.

9. Asbjornsen AE, Obrzut JE, Boliek CA, Myking E, Holmefjord A, Reisaeter S, et al. Impaired auditory attention skills following middleear infections. Child Neuropsychol. 2005;11(2):121-33.

10. Hartley DE, Moore DR. Effects of otitis media with effusion on auditory temporal resolution. Int $\mathbf{J}$ Pediatr Otorhinolaryngol. 2005;69(6):757-69.

11. Keogh T, Key J, Driscoll C, Cahill L, Hoffmann A, Wilce E, et al. Measuring the ability of school children with a history of otitis media to understand everyday speech. J Am Acad Audiol. 2005;16(5):301-11.

12. Eapen RJ, Buss E, Grose JH, Drake AF, Dev M, Hall JW. The development of frequency weighting for speech in children with a history of otitis media with effusion. Ear Hear. 2008;29(5):718-24.

13. Maruthy S, Mannarukrishnaiah J. Effect of early onset otitis media on brainstem and cortical auditory processing. Behav Brain Funct. 2008;4(17):1-13.

14. Zumach A, Gerrits E, Chenault MN, Anteunis LJC. Otitis media and speech-in-noise recognition in school-age children. Audiol Neurotol. 2009;14(1):121-9.

15. Whitton JP, Polley DB. Evaluating the perceptual and pathophysiological consequenses of auditory deprivation in early postnatal life: a comparison of basic and clinical studies. J Assoc Res Otolaryngol. 2011;12(5):535-46.

16. Borges LR, Paschoal JR, Colella-Santos MF. (Central) auditory processing: the impact of otitis media. Clinics. 2013;68(7):954-9.

17. Johnson MH. Sensitive periods in functional brain development: problems and prospects. Dev Psychobiol. 2005;46(6):287-92.

18. Hutson KA, Durham D, Tucci DL. Reversible conductive hearing loss: restored activity in the central auditory system. Audiol Neurootol. 2009;14(2):69-77.

19. American Academy of Audiology [Internet]. American Academy of Audiology Clinical Practice Guidelines: 2010. Diagnosis, treatment and management of children and adults with central auditory processing disorder [cited 2010 Aug 24]. Available from: http://www. audiology.org/resources/documentlibrary/documents/capd 
20. Auditec. Evaluation manual of pitch pattern sequence and duration pattern sequence. Missouri: Auditec; 1997.

21. Musiek FE, Shinn JB, Jirsa R, Bamiou JA. GIN (Gaps-In-Noise) test performance in subjects with confirmed central auditory nervous system involvement. Ear Hear. 2005;26(6):608-18.

22. Ungkanont K, Charuluxananan S, Komoltri C. Association of otoscopic findings and hearing level in pediatric patients with otitis media with effusion. Int J Pediatr Otorhinolaryngol. 2010;74(9):1063-6.

23. Hartley DE, Moore DR. Effects of conductive hearing loss on temporal aspects of sound transmission through the ear. Hear Res.2003;177(1-2):53-60.

24. Shinn JB. Temporal processing tests. In: Musiek FE, Chermak GD. Handbook of central auditory processing disorder: auditory neuroscience and diagnosis. Volume I. San Diego: Plural Publishing; 2014; p. 405-34.

25. Schochat E, Rabelo CM, Sanfins MD. Processamento auditivo central: testes tonais de padrão de freqüência e de duração em indivíduos normais de 7 a 16 anos de idade. Pró-fono. 2000;12(2):1-7.

26. Balen SA. Reconhecimento dos padrões auditivos de frequência e de duração: desempenho de crianças escolares de 7 a 11 anos [tese]. São Paulo: Universidade de São Paulo; 2001.
27. Shinn JB, Chermak GD, Musiek FE. GIN (Gap-In-Noise) performance in the pediatric population. J Am Acad Audiol. 2009;20(4):229-38.

28. Amaral IRA, Colella-Santos MF. Temporal resolution: performance of school-age in the GIN - Gaps-in-noise test. Braz J Otorhinolaryngol. 2010;76(6):745-52.

29. Marculino CF, Rabelo CM, Schochat E. Gaps-in-Noise test: gap detection thresholds in 9-year-old normal-hearing children. J Soc Bras Fonoaudiol. 2011;23(4):364-7.

30. Schochat E, Musiek FE. Maturation of outcomes of behavioral and electrophysiologic tests of central auditory function. J Commun Disord. 2006;39(1):78-92.

31. Neves IF, Schochat E. Maturação do processamento auditivo em crianças com e sem dificuldades escolares. Pró-fono. 2005;17(3):311-20.

32. Møller AR, Janetta PJ, Møller MR. Neural generators of brain-stem evoked potentials. Results from human intracranial recordings. Ann Otol Rhinol Laryngol.1981;90:591-6.

33. Haapala S, Niemitalo-Haapola E, Raappana A, Kujala T, Suominen $\mathrm{K}$, Kujala T, et al. Effects of recurrent acute otitis media on cortical speech-sound processing in 2-year old children. Ear Hear. 2014;35(3):e75-83. 